\title{
The Effect of Fenugreek and WPI on Release of Aromatic Acids from Shiraz Cheese - Iranian Traditional Cheese Produced from Bovine Milk
}

\author{
M. Aminifar
}

\begin{abstract}
In this study, the effect of fenugreek and whey protein isolate (WPI 85) on the release of acids from Shiraz cheese texture was investigated over 30 days of storage. Fenugreek and WPI 85 were used to modify the textural properties of low fat Shiraz cheese produced from bovine milk. Physicochemical properties, hardness (by texture analyzer), microstructure (by scanning electron microscopy (SEM)) and the amount of aroma release (by solid phase microextraction gas chromatography (SPME-GC-MS) of different types of Shiraz cheese were investigated. Textural parameters and microstructure of cheese matrix were affected by addition of fenugreek and WPI 80. In the presence fenugreek and WPI 80, the hardness of bovine Shiraz cheese was increased. The compaction of casein matrix was decreased when the bovine milk was used for cheese production due to decrease in casein content of milk. Addition of fenugreek and WPI play an important role in compaction of casein network. The release of acids from cheese matrix was affected by interaction of WPI-casein and fenugreek-casein. The Release of acids from cheese containing WPI could be related to the presence of B-lactoglobulin which has several binding sites.
\end{abstract}

Index Terms-Acids, Shiraz cheese, fenugreek, WPI.

\section{INTRODUCTION}

Shiraz cheese is a traditional cheese which is produced in west and northwest of Iran from ovine milk. Due to the limitations existed in production of sheep milk, ovine milk is substituted by bovine milk by some producers. When ovine milk is substituted by bovine milk, the textural properties of cheese were adversely affected due to the decrease in fat and protein content. Texture is one of the key characteristics for evaluation of cheese quality. This parameter was affected by several factors such as the kind of milk used for cheese making, production line and etc. Sheep milk is basically different from cow's milk due to its higher total solids - fat, solid non-fat, protein, casein- than cow milk. The textural parameters of low fat cheese were improved by the addition of polysaccharides and whey protein concentrate (WPC) [1]. The role of two types of carrageenan on the low fat Oaxaca cheese texture was previously reported [2]. Reduced fat Cheddar cheese quality was enhanced in the presence of Xanthan gum and sodium caseinate [3]. Fenugreek gum which is a galactomannan polysaccharide -obtained from the endosperm of the seeds of the plant (Trigonella

Manuscript received April 13, 2015; revised June 23, 2015.

M. Aminifar is with the Department of Food science \& Technology, Faculty of Food Industry and Agriculture, Standard Research Institute (SRI), Karaj P. O. Box 31745-139, Islamic Republic of Iran (e-mail: aminifar.m@standard.ac.ir) foenum-graecum L.), with the 1:1 ratio of galactose and mannose- could be used as a soluble dietary fibre component and improve textural properties of food matrixes. Medicinal properties of seed are due to soluble dietary fibres. Since this gum could not metabolized in human system, could act as dietary

Fiber has higher efficacy in lowering blood glucose and LDL in comparison with other dietary fibres. Thus, it is considered as good option for consumption by obese and diabetic persons [4]. The chemical structure of fenugreek was presented in Fig. 1.

There are several methods for evaluation of cheese textural properties such as uniaxial compression, rheological tests and scanning electron microscopy.

Reducing the fat disturbs the balance intense flavour. The rate of aroma release from the food texture to the air depends on volatility of the aroma compounds from the food matrix (thermodynamic factor) and the resistance to mass transfer (kinetic factor) [5]. When the polysaccharid and protein were added to the food matrix, the changes in kinetic factor of aromatic compounds occurred. Addition of polysaccharide and protein for modifying the textural properties of low fat cheese resulted to the change in kinetic factor of aromatic compounds and aroma release from cheese texture. In this research, the effect of fenugreek gum and WPI 80 on the texture and aroma release of low fat Shiraz cheese during the 30 days of the storage was investigated.

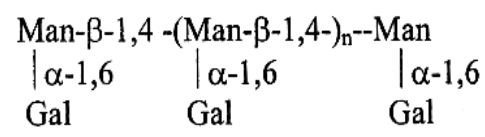

Fig. 1. Fenugreek chemical structure.

\section{MATERIALS AND METHOD}

\section{A. Shiraz Cheese Production}

Shiraz cheeses were produced from ovine and bovine milk containing $6.5 \%$ and $2.5 \%$ fat, respectively. For production of bovine cheese containing fat replacer, $0.02 \%$ fenugreek or WPI80 were added to the milk. For production of Shiraz cheese, raw was heated at $85{ }^{\circ} \mathrm{C}$ for 15 minutes and then cooled to $42{ }^{\circ} \mathrm{C}$. The milk was inoculated by the yoghurt starter $(1.5 \%)$ and stored at $42{ }^{\circ} \mathrm{C}$ for 4 hours. After fermentation time, the fermented milk was cooled to $6{ }^{\circ} \mathrm{C}$ and maintained at that temperature for 14-16 hours. The cooled fermented milk was mixed with $1250 \mathrm{rpm}$ for 40 minutes and then the serum was separated. The serum was heated at $90{ }^{\circ} \mathrm{C}$ for 15 minutes and then cooled to $20{ }^{\circ} \mathrm{C}-30{ }^{\circ} \mathrm{C}$. Afterwards, the whey of the product was separated by the thin tissue for 
18 hours and $1 \%$ salt was added to the cheese texture and then stored for 1 month. For cheese flavoring, $0.1 \%$ butanoic acid, hexanoic acid and decanoic acid (Sigma-Aldrich, Germany) were added to the cooled milk after the heating.

\section{B. Physicochemical Characteristics}

The moisture content of Shiraz cheese was measured according to the standard (4A) FIL-IDF [6]. The pH of Shiraz cheese samples was determined by a Knick 766 pH-meter calimatic (Niels, Bohrweg, Utrecht, The Netherlands). Salt content of cheese samples was measured according to Kirk and Sawyer's method [7].

\section{Textural Properties}

Shiraz cheese hardness during the storage was evaluated by texture analyzer (Testometric M350-10CT, England) fitted with a $0-50 \mathrm{~kg}$ load cell. Cheese cube samples $(20 \times 20 \times 20 \mathrm{~mm})$ adjusted to $12 \pm 5^{\circ} \mathrm{C}$ were compressed to $70 \%$ of their initial height with a plunger, $40 \mathrm{~mm}$ in diameter and $30 \mathrm{~mm} / \mathrm{min}$ speed.

\section{Microstructure}

Before scanning electron microscopy (SEM) analysis, cheese samples after 30 days of ripening, should be prepared according to [8] method with some modifications suggested by [9]. This method is composed of three main stages including fixation in gluteraldehyde, dehydration with series of ethanol and de fatting in chloroform. According to this method, cheese cubes (5 to $6 \mathrm{~mm} 3$ ) were immersed in $2.5 \%$ (w/w) gluteraldehyde fixative (Merck Chemical Ltd., Darmstadt, Germany) for 3 hours. Fixed cubes were washed in six changes of distilled water (1 minute each). In the next stage, the washed cubes were immersed in a graded $(40,55$, $70,85,90$ and $96 \%$ ) series of ethanol for 30 minutes at each grade for dehydration, and then their fat was separated with three changes of chloroform (10 minutes each). The prepared cubes had been storage in ethanol $96 \%$. Before test, the cubes were fractured in liquid nitrogen and were coated by gold. The 3D images of the SEM micrographs were drawn by image J software (ImageJ, National Institutes of Health, Bethesda, MD). These settings were applied to obtain 3D-images: $z$ ratio: 0.18 , smoothing: 12.0 , lightening: 0.2 , scale: 1.34 and grid size: 512. Binarised images were obtained by the software menu too.

\section{E. SPME-GC-MS}

Aroma release from cheese matrix after 30 days of ripening was evaluated with [10] method. For all extractions, DVB/CAR/PDMS[divinylbenzene/carboxen/polydimethylsi loxane] fiber, $50 / 30 \mu \mathrm{m}$ film thickness bonded to a flexible fused silica core (Supelco), was used.

For better determination of aroma release from cheese texture, five grams of Shiraz cheese was dissolved in $10 \mathrm{ml}$ water in a $40 \mathrm{ml}$ vial. For better insertion of fiber without any leakage, the "mininert" valve (Supelco) was used. The equilibrium time was considered for $10 \mathrm{~min}$ at $50{ }^{\circ} \mathrm{C}$. After this stage, the coated fiber was placed in the headspace for $1 \mathrm{~h}$ at $60{ }^{\circ} \mathrm{C}$. For desorption of volatile compounds, during extraction period, the sample was blended steadily with a magnetic stir bar on a stir-plate rotating at $750 \mathrm{rpm}$. For desorption of volatile compounds, the fiber was inserted for 5 min into the injection port of the GC (splitless mode) adjusted at $250{ }^{\circ} \mathrm{C}$. The volatile compounds were determined by an Agilent HP 6890N gas chromatography (Agilent Technologies, Palo Alto, CA) equipped with an Agilent $5973 \mathrm{~N}$ mass-selective detector operating in electron impact mode (ionization voltage, $70 \mathrm{eV}$ ). The type of detector used for this analysis was mass-selective operated in the total ion current (TIC) mode, scanning from 20 to $500 \mathrm{~m} / \mathrm{z}$. A DB-Wax column capillary column $(30 \mathrm{~m} \times 0.25 \mathrm{~mm}$ I.D., 0.5 $\mu \mathrm{m}$ film thickness) was applied (Supelco). Helium (>99.999\% pure) was selected as carrier gas with flow rate of $1.2 \mathrm{~mL}$ min-1. The GC oven temperature was set at this program: initial temperature $45^{\circ} \mathrm{C}$ for $1 \mathrm{~min}$ then up to $250{ }^{\circ} \mathrm{C}$ at $5{ }^{\circ} \mathrm{C}$ $\min -1$ and $5 \mathrm{~min}$ at that temperature.

\section{F. Statistical Analysis}

For the statistical analysis of the experimental data, SAS statistical software (version 8.2, SAS Institute Inc., Cary, NC) was used. Duncan's test was applied to compare between mean values of the volatile compounds and hardness for different days of storage. Evaluation was based on a significance level of $p<0.05$.

\section{RESULTS AND DISCUSSION}

\section{A. Physicochemical Characteristics}

Changes in physicochemical characteristics of different types of Shiraz cheese were shown in Table I.

TABLE I: CHANGE IN PHYSICOCHEMICAL CHARACTERISTCS DURING STORAGE

\begin{tabular}{lccc}
\multicolumn{4}{c}{ STORAGE } \\
PH & \multicolumn{1}{c}{$\mathbf{1}$} & $\mathbf{1 5}$ & $\mathbf{3 0}$ \\
bovine & $4.2^{\mathrm{a}}$ & $4.0^{\mathrm{b}}$ & $3.8^{\mathrm{c}}$ \\
WPI & $4.3^{\mathrm{a}}$ & $4.0^{\mathrm{b}}$ & $3.7^{\mathrm{c}}$ \\
Fenugreek & & & \\
& $4.1^{\mathrm{a}}$ & $3.8^{\mathrm{b}}$ & $3.5^{\mathrm{c}}$
\end{tabular}

$\begin{array}{llll}\text { Moisture \% } & & & \\ \text { bovine } & 80.5^{\mathrm{a}} & 75.2 \mathrm{~b} & 70.2^{\mathrm{c}} \\ \text { WPI } & 74.1^{\mathrm{a}} & 70.3^{\mathrm{b}} & 68.2^{\mathrm{c}} \\ \text { Fenugreek } & 83.1^{\mathrm{a}} & 80.1^{\mathrm{b}} & 78.2^{\mathrm{c}}\end{array}$

Salt \%

$\begin{array}{llll}\text { bovine } & 0.5^{\mathrm{c}} & 1.5^{\mathrm{b}} & 2.7^{\mathrm{a}} \\ \text { WPI } & 0.5^{\mathrm{c}} & 1.3^{\mathrm{b}} & 2.0^{\mathrm{a}} \\ \text { Fenugreek } & 0.3^{\mathrm{c}} & 1.4^{\mathrm{b}} & 2.3^{\mathrm{a}}\end{array}$

a-c. Different letters in each row are significantly different $(\mathrm{P}<0.05)$

The $\mathrm{pH}$ of cheese samples is affected by two main factors: fermentative activity of micro-organisms and production of amine groups by micro-organisms. Since Shiraz cheese was heated during the process, the population of proteolytic microorganisms was decreased and therefore the fermentative activity of microorganisms is the dominant factor for $\mathrm{pH}$.

The $\mathrm{pH}$ of all samples was decreased during the storage due to lactose fermentation [10]. The $\mathrm{pH}$ of samples was not affected by addition of fenugreek and WPI. Similar results were reported by [1], who reported that the addition of polysaccharide did not affect the cheese $\mathrm{pH}$. The moisture content of cheese samples was decreased during the ripening which could be related to the diffusion of the salt to the 
texture. Similar results were reported by the authors [1]. The moisture content of cheese samples was affected by the polysaccharide and protein addition. Addition of WPI increased solid content of the cheese matrix whereas addition of fenugreek increased cheese moisture content due to its water holding capacity. The salt content of the cheese was increased during the aging which could be related to diffusion of the salt to cheese matrix. Addition of WPI and fenugreek affect the diffusion of the salt to cheese matrix. The change in textural properties of Shiraz cheese by addition of WPI and fenugreek, could play an important role in salt diffusion.

\section{B. Textural Properties}

Changes in hardness of different types of Shiraz cheese were shown in Fig. 2.

Since the salt crystals were added to the cheese, water was expelled from the Shiraz cheese texture during the first 10 days of storage and therefore, the hardness of the samples was increased. After 10 days of storage, the hardness of Shiraz cheese did not change significantly, due to the equilibrium between protein degradation as a result of proteolysis which soften the texture and water expel as a result of salt crystal osmotic pressure.

Hardness of ovine Shiraz cheese increased when the ovine milk is substituted by bovine milk due to decrease in fat which has plasticizing effect. Pappa et al. (2007) showed that hardness of Teleme cheese was affected by type of milk. They reported that goat's cheese was significantly harder $(5.6-8.9 \mathrm{~kg})$ than cow's $(3.3-5.0 \mathrm{~kg})$ and sheep's $(3.7-6 \mathrm{~kg})$ [11].

Hardness of bovine cheese increased when WPI were added to bovine milk which could be related to the increase in protein content which has force bearing characteristics [12]. The hardness of bovine Shiraz cheese was decreased, when fenugreek was added to the bovine milk which could be related to the increase in moisture content of the cheese, due to water binding capacity of the gum.

\section{Microstructure}

Fig. 3 shows that density of the caseins in ovine Shiraz cheese decreased when bovine milk is used for cheese production. The higher density of casein aggregates in ovine cheese could be related to higher level of solid content in ovine cheese [13]. Microstructure of bovine Shiraz cheese was affected by the addition of fenugreek and WPI. Addition of fenugreek resulted to the more open casein network and water was entrapped. Open microstructure of Shiraz cheese containing WPI could be related to the presence of soluble proteins including caseinomacropeptide (CMP) which has water adsorption characteristics.

The density of black patches is decreased when the bovine milk is used for production of Shiraz cheese. In similar way, the white patches were increased in binarised micrographs. Addition of fenugreek and WPI80 resulted to decrease in compaction of black patches which was accompanied with increase in white parts in binarised micrographs.

\section{Aroma Release Determination}

Table I showed that acid release from Shiraz cheese is affected by acid molecular weight and addition of polysaccharide and protein. Some researchers reported [5] that, the release of aromatic compounds from the gel was affected by its textural properties. Since the hardness of Shiraz cheese containing WPI, was higher than bovine Shiraz cheese, the release of acids from that was lower than samples with no additive (Table I). The presence of $B$-lactoglobulin in WPI, also played an important role in the decrease of acids release from the Shiraz cheese texture due to its binding sites $[5]$.

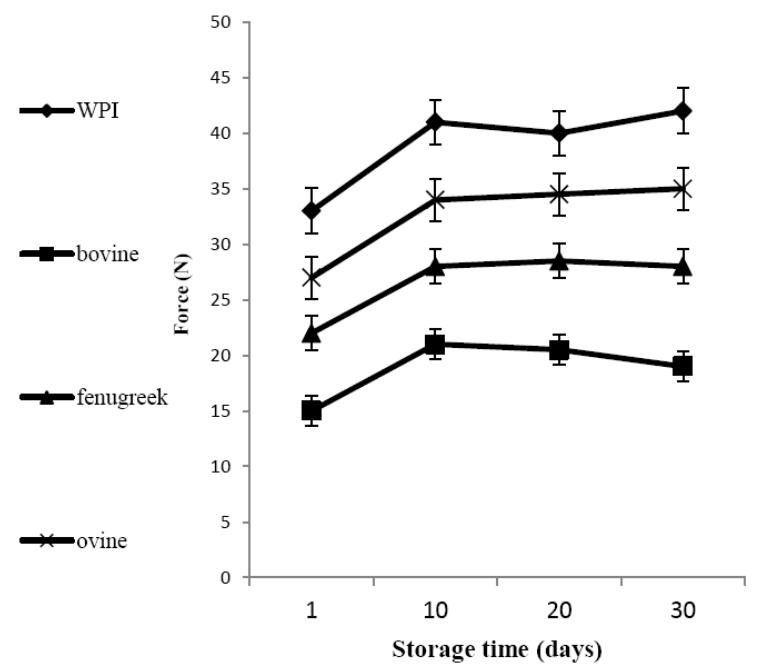

Fig. 2. Changes in hardness of Shiraz cheese produced from different type of milks $(p<0.05)$.
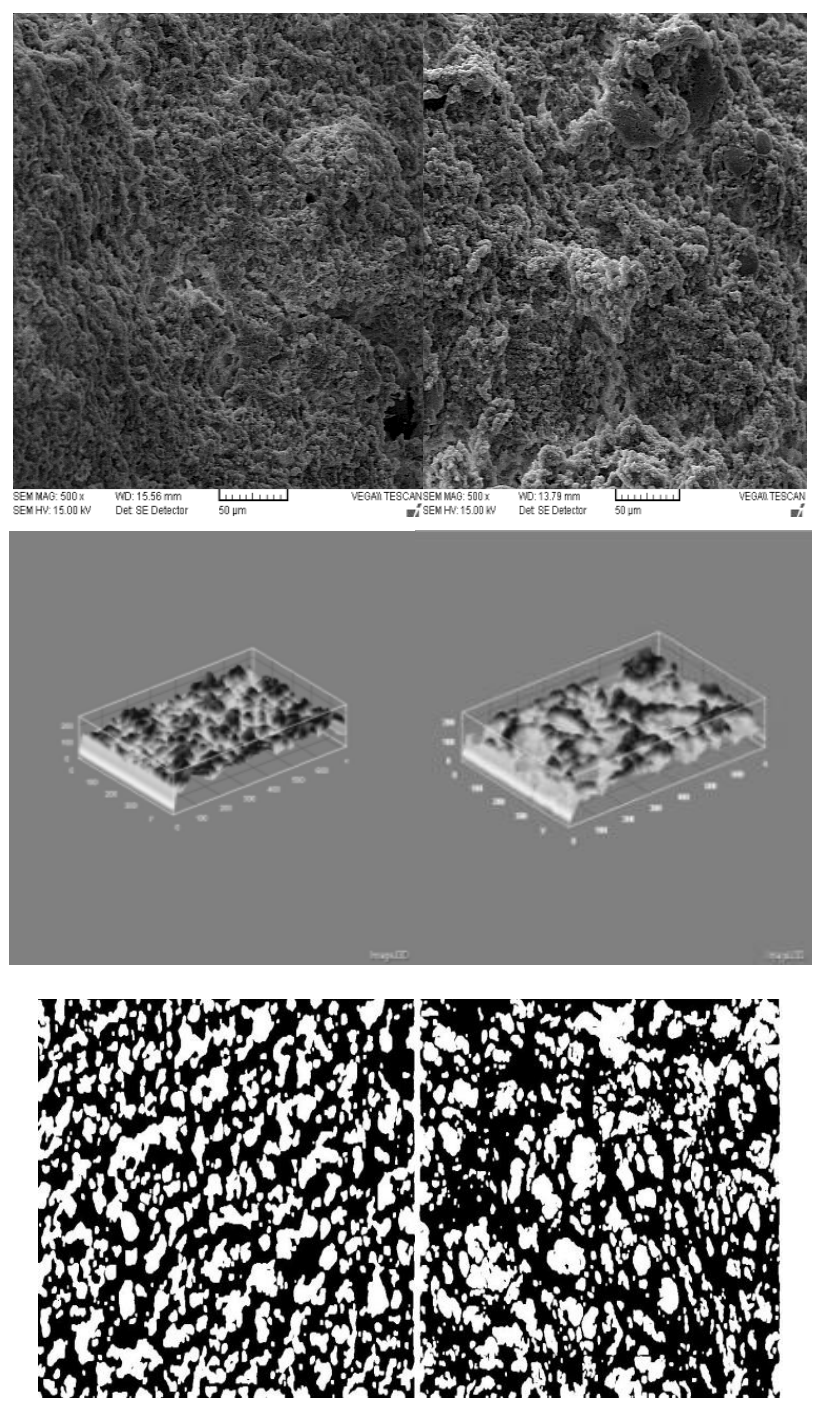

Ovine

Bovine 

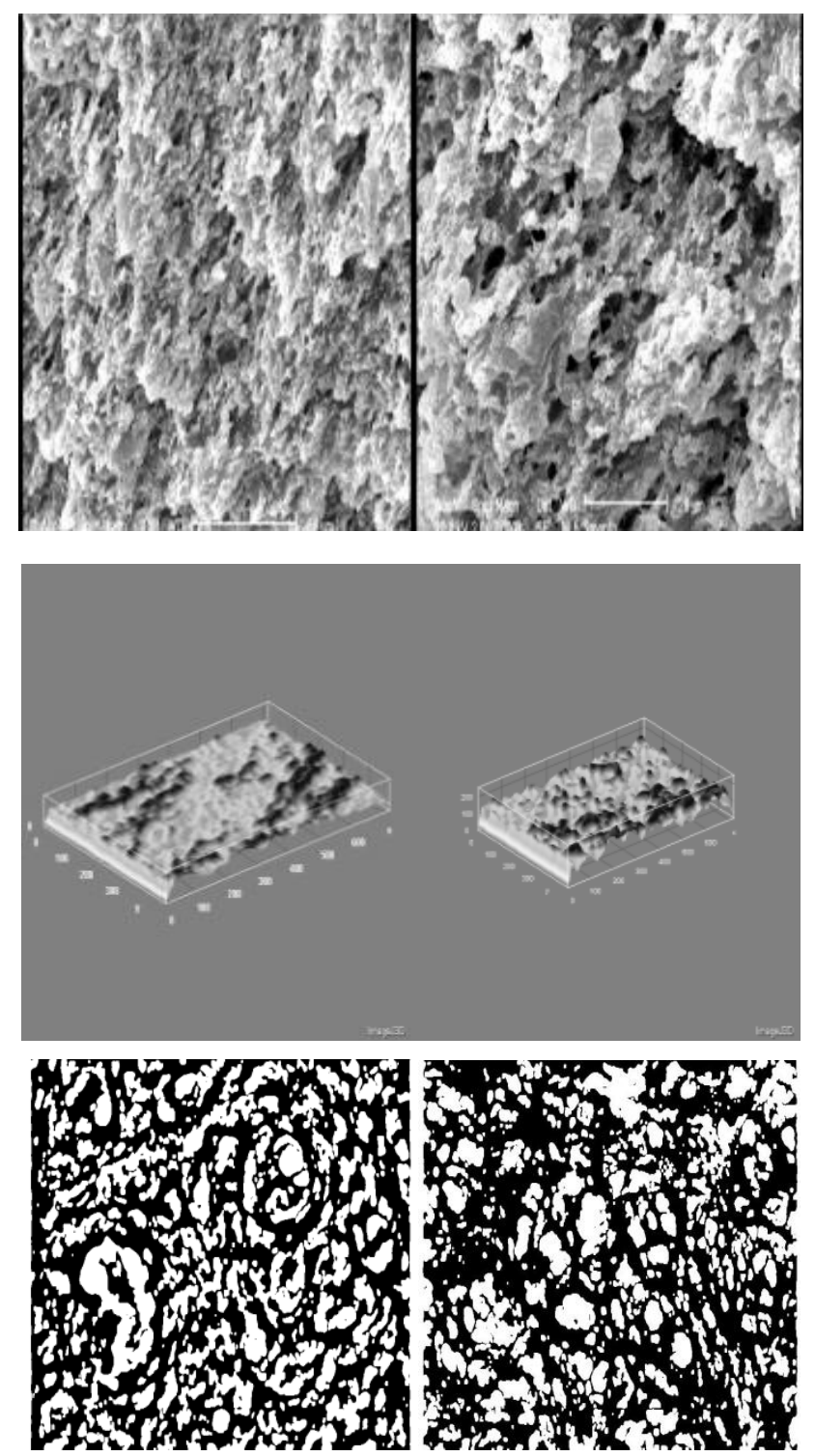

fenugreek

WPI 80

Fig. 3. Microstructue of Shiraz cheese produced from different type of milks. 3D- images and binarised SEM micrographs of each images were shown in below of each SEM micrographs.

TABLE II: AREA PEAK OF ACIDS RELEASED FROM DIFFERENT TYPES OF SHIRAZ CHEESE

\begin{tabular}{lccl}
\hline Acids & bovine & WPI & fenugreek \\
Buanoic acid & $12.4^{\mathrm{a}}$ & $9.4^{\mathrm{c}}$ & $11.4^{\mathrm{b}}$ \\
& & & \\
Hexanoic acid & $10.5^{\mathrm{a}}$ & $7.3^{\mathrm{c}}$ & $9.1^{\mathrm{b}}$ \\
Decanoic acid & $9.4^{\mathrm{a}}$ & $6.1^{\mathrm{c}}$ & $8.5^{\mathrm{b}}$ \\
\hline
\end{tabular}

a-c. Different letters in each row are significantly different $(p<0.05)$

Addition of fenugreek to Shiraz cheese decreased the acids release from the cheese texture significantly as a result of acid entrapment in the gel network produced as a result of water binding capacity of polysaccharide.

\section{CONCLUSIONS}

Several factors played an important role in release of acids from Shiraz cheese such as textural parameter, the presence of ligands and polysaccharide compounds. The release of acids was decreased from Shiraz cheese in the presence of fenugreek and WPI which could be related to the increase in the hardness, binding sites of $B$-lactoglobulin in WPI and water binding capacity of fenugreek.

\section{ACKNOWLEDGMENT}

This work was supported by Standard Research Institute (SRI), Karaj, Iran.

\section{REFERENCES}

[1] J. Rahimi, A. Khosrowshahi, A. Madadlou, and S. Aziznia, "Texture of low-fat Iranian white cheese as Influenced by Gum Tragacanth as a fat replacer," Journal of Dairy Science, vol. 90, pp. 4058-4070, 2007.

[2] A. Totosaus and N. Guemes-Vera, "Effect of k- and 1-Carrageenans as Fat-replacers in low-fat Oaxaca cheese," International Journal of Food Properties, vol. 11, 2008, pp. 656-668.

[3] L. Nateghi et al., "Physicochemical and textural properties of reduced fat cheddar cheese formulated with Xanthan gum and/or sodium caseinate as fat replacers," Journal of Food, Agriculture \& Environment, vol. 10, pp. 59-63, 2012.

[4] V. Mathur and N. K. Mathur, "Fenugreek and other lesser known legume galactomannan-polysaccharides: Scope for developments," Journal of Scientific \& Industerial Research, vol. 64, pp. 475-481, 2005.

[5] K. B. de Roos, "Effect of texture and microstructure on flavour retention and release," International Dairy Journal, vol. 13, pp. 593-605, 2003.

[6] Fil-IDF, "Standard '4 A', Determination the total solid content (Reference method)," in Cheese and Processed Cheese, International Dairy Federation, pp. 110-115, 1982.

[7] S. Kirk and R. Sawyer, "Pearson's composition and analysis of foods," Longman Science and Technical, 1991.

[8] M. A. Drake, W. Herrett, T. D. Boylston, and B. G. Swanson, "Lecithin improves texture of reduced fat cheeses," Journal of Food Science, vol. 47, pp. 639-642, 1996.

[9] A. Madadlou, A. Khosrowshahi, M. E. Mousavi, Z. Emam Djome, and M. Zargaran, "The influence of brine concentration on chemical composition and texture of Iranian white cheese," Journal of Food Engineering, vol. 81, pp. 330-335, 2007.

[10] M. Aminifar, M. Hamedi, Z. Emam-Djome, and A. Mehdinia, "The effect of ovine and bovine milk on the textural properties of Lighvan cheese during ripening," International Dairy Journal, vol. 81, pp. 330-335, 2007.

[11] E. C. Pappa, I. Kandarakis, and H Mallatou, "Effect of different types of milks and cultures on the rheological characteristics of Teleme Cheese," Journal of Food Engineering, vol. 79, pp. 143-149, 2007.

[12] P. D. Veith and E. C. Reynolds, "Production of a high gel strength whey protein concentrate from cheese whey," Journal of DairyScience, vol. 65 , pp. 45-53, 2013.

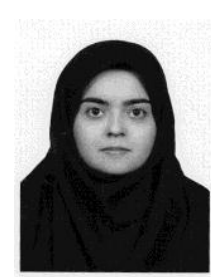

M. Aminifar was born in Iran in 1981. She received BSc of food science and technology from Isfahan University of Technology in 2003. Then, she followed her studies and received MSc and $\mathrm{PhD}$ from Tehran University. Now, she is working as a faculty member of Food Science and Technology Department at Standard Research Centre in Iran.

Her publications are on-line in the field of cheese in International Dairy Journal, Journal of Texture studies, Journal of Food Science and Technology and Nutrition and food sciences research.

M. Aminifar is a reviewer of Iranian Journal of Biosystem Engineering. 
